\title{
Relation of interleukin-15 with the severity of primary knee osteoarthritis
}

\author{
Ibrahim K. Ibrahim ${ }^{\mathrm{a}}$, Emmanuel K. Aziz Saba ${ }^{\mathrm{a}}$, Neveen L. Mikhael Saad ${ }^{\mathrm{b}}$, \\ Doaa Y.A. Mohammed ${ }^{\mathrm{C}}$
}

\author{
Departments of ${ }^{\mathrm{a}}$ Physical Medicine, \\ Rheumatology and Rehabilitation, ${ }^{\mathrm{b}} \mathrm{Clinical}$ and \\ Chemical Pathology, Faculty of Medicine, \\ Alexandria University, ${ }^{C}$ Physical Medicine, \\ Rheumatology and Rehabilitation Department, \\ Ministry of Health Hospitals, Ministry of Health, \\ Alexandria, Egypt \\ Correspondence to Emmanuel K. Aziz Saba, \\ MD, Physical Medicine, Rheumatology and \\ Rehabilitation Department, Faculty of Medicine, \\ Alexandria University, Alexandria, 21131. \\ Egypt \\ Tel: +20 1224718376 ; \\ e-mail: emadaziz55@yahoo.com \\ Received 19 May 2019 \\ Accepted 20 June 2019
}

Egyptian Rheumatology \& Rehabilitation 2019, 46:313-320

\begin{abstract}
Background
Interleukin-15 (IL-15) is a proinflammatory cytokine. IL-15 could be considered a potential biomarker for primary knee osteoarthritis (OA).

Aim

This study aimed to assess the serum level of IL-15 in primary knee OA patients and assess its relation to clinical severity, functional disabilities, and radiological grading of knee OA.

Patients and methods

This study included 40 patients with primary knee OA and 40 apparently healthy individuals. Assessment of knee OA was performed using clinical examination, the Western Ontario and McMaster Universities Osteoarthritis Index score, and Health Assessment Questionnaire-Disability Index. Radiological assessment was performed using the Kellgren-Laurence grading scale. Serum level of IL-15 was measured in both patients and control participants.
\end{abstract}

\section{Results}

There were no statistically significant differences between patients and the control group in sex $(P=1.000)$ and age $(P=0.247)$. The patient group had a statistically significantly higher serum IL-15 level than its level in the control group $(P \leq 0.0001)$. Serum IL-15 level was significantly higher among patients with knee joint line tenderness and effusion $(P \leq 0.0001)$. There were statistically significant positive correlations between serum IL-15 level with the Western Ontario and McMaster Universities Osteoarthritis Index total score $(P \leq 0.0001)$, the Health Assessment Questionnaire-Disability Index score $(P \leq 0.0001)$, and the Kellgren-Laurence grading scale $(P \leq 0.0001)$.

\section{Conclusion}

Serum IL-15 is elevated and correlated positively with pain, stiffness, functional disabilities, as well as radiological damage in primary knee OA. This suggests that IL-15 plays an important critical role in the pathogenesis of primary knee OA-related pain, stiffness, and joint damage. IL-15 might be a potential biomarker for assessing the severity of primary knee OA.

\section{Keywords:}

interleukin-15, Kellgren-Laurence grading, osteoarthritis, primary knee osteoarthritis, Western Ontario and McMaster universities osteoarthritis index

Egypt Rheumatol Rehabil 46:313-320

(c) 2019 Egyptian Society for Rheumatology and Rehabilitation

$1110-161 X$

\section{Introduction}

Osteoarthritis (OA) is a common articular degenerative disorder that affects mainly the knee joints. The most common form is primary OA [1]. It is a common cause of musculoskeletal disability worldwide [2,3]. The pathogenesis of primary $\mathrm{OA}$ is complex and involves several cytokines such as interleukins and adipocytokines [4,5]. It is known that the proinflammatory cytokines are essential mediators implicated in the pathophysiology of knee OA $[6,7]$.

It is important for detection of biochemical markers that could assess the OA progression and determine its severity early enough before radiological joint damage takes place. Inflammation is believed to play a critical role in the pathogenesis of OA. Subsequently, the inflammatory mediators that are released in $\mathrm{OA}$ could be considered as important mediators in the pathogenesis of OA. They could be candidates for biochemical markers for OA severity and progression [8].

Interleukin-15 (IL-15) is a proinflammatory cytokine. It plays a role in the regulation of $\mathrm{T}$-cells and the activation and proliferation of natural killer cells $[6,9]$. IL-15 could be considered a potential biomarker for

This is an open access journal, and articles are distributed under the terms of the Creative Commons Attribution-NonCommercial-ShareAlike 4.0 License, which allows others to remix, tweak, and build upon the work non-commercially, as long as appropriate credit is given and the new creations are licensed under the identical terms. 
primary knee OA. Very few studies have assessed the role of IL-15 in primary knee OA and its relation to OA severity and progression $[10,11]$.

The aim of this study was to assess the serum level of IL-15 in primary knee OA patients and assess its relation to clinical severity, functional disabilities, and radiological grading of knee $\mathrm{OA}$.

\section{Patients and methods}

This cross-sectional study included 40 patients with primary knee OA diagnosed according to the clinical and radiographic criteria of the American College of Rheumatology criteria for the classification of primary knee OA (1986) [12]. Patients were recruited from among those attending the outpatient clinic of Physical Medicine, Rheumatology and Rehabilitation Department, Alexandria Main University Hospital. Exclusion criteria included patients with diabetes mellitus, endocrine disorders, overlap with other rheumatologic diseases, traumatic arthritis, secondary $\mathrm{OA}$, and patients with diseases in which IL-15 increased such as inflammatory bowel diseases. The study included 40 apparently healthy volunteers as a control group. The study was explained to the participants. Each participant provided an informed consent. This study was approved by the Ethics Committee of the Faculty of Medicine, Alexandria University, Egypt.

All the patients studied were subjected to demographic data collection, anthropometric measurements, which included height, body weight, and body mass index (BMI), and musculoskeletal examination focusing on both knees. Assessment of primary knee OA severity was performed using the Western Ontario and McMaster Universities Osteoarthritis Index (WOMAC). The WOMAC has three different subscales for the assessment of pain, stiffness, and function. The scores are summed for items in each subscale. The total WOMAC score of the three subscales was graded as follows: mild (from 0 to 24), moderate (from 25 to 48), severe (from 49 to 72 ), and extreme (from 73 to 96) [13]. Functional assessment was performed using the Health Assessment Questionnaire-Disability Index (HAQ-DI). The HAQ-DI score of $0-1$ is considered to represent mild to moderate functional disability, more than 1-2 to represent moderate to severe functional disability, and more than 2-3 to represent severe to very severe functional disability [14]. Radiological grading of knee OA severity was performed using the Kellgren-Laurence (K/L) grading scale. The radiological severity was categorized into four grades as follows: very mild (grade 1), mild (grade 2), moderate (grade 3), and severe (grade 4) [15]. Laboratory investigation in the form of measurement of IL-15 serum level was performed using the enzymelinked immunosorbent assay (ELISA) technique for the quantitative detection of IL-15. This was performed using human IL-15 ELISA kit (81275C, ElAab; WUHAN EIAAB Science, Wuhan, China) read on ELISA reader (Stat-Fax 2100; Awareness Technology Inc., Palm City, Florida, USA).

Statistical analysis of data was carried out using the statistical package of the social sciences (SPSS version 17) software (University of Cambridge computing service, London, United Kingdom) [16]. This included descriptive measures and analytic measures. The descriptive measures included the count, frequency, minimum, maximum, median, mean, and standard deviation (SD). The analytic measures included the Mann-Whitney test, the Kruskal-Wallis test, the Chi-square test, and the Spearman correlation test. Statistical significance was assigned to any $P$ value at less than 0.05 . The reference cut-off value of serum IL-15 was calculated by rounding the mean plus two $\mathrm{SD}$ to measure the upper limit of normal.

\section{Results}

This study included 40 patients with primary knee OA [30 (75\%) females]. Their mean age was $54.15 \pm 5.18$ years (ranged from 45 to 65 years). The study included 40 apparently healthy volunteers [30 (75\%) females] as a control group. Their mean age was $52.95 \pm 4.13$ years (ranged from 48 to 65 years). There were no statistically significant differences between patients and controls in sex $\left(\chi^{2}=0.000, \quad P=1.000\right)$ and age $(Z=-1.158$, $P=0.247)$. Different demographic data and anthropometric measures of the patients and control groups are summarized in Table 1 . Different clinical characteristics and radiological assessment of the patients are summarized in Table 2.

The patient group had a statistically significantly higher serum IL-15 level than its level in the control group $(P \leq 0.0001$; Table 3 and Fig. 1$)$. The reference cut-off value for the serum IL-15 level obtained from the apparently healthy individuals was up to $43.1 \mathrm{pg} / \mathrm{ml}$. An elevated serum level of IL-15 was considered if it was above its cut-off value. In 37 (92.5\%) patients, the serum IL-15 level exceeded its reference cut-off value.

The patient group with knee joint line tenderness had a statistically significantly higher serum IL-15 level than 
Table 1 Different demographic data and anthropometric measures of the patient and the control groups

\begin{tabular}{|c|c|c|c|c|}
\hline $\begin{array}{l}\text { Different demographic data and anthropometric } \\
\text { measures }\end{array}$ & $\begin{array}{c}\text { Patient group }(n=40) \text { (mean } \\
\pm S D)\end{array}$ & $\begin{array}{c}\text { Control group }(n=40) \text { (mean } \\
\pm S D)\end{array}$ & $\begin{array}{c}\text { Test of } \\
\text { significance }\end{array}$ & $P$ \\
\hline Age (years) & $54.15 \pm 5.18$ & $52.95 \pm 4.13$ & $Z=-1.158$ & 0.247 \\
\hline Women $[n(\%)]$ & $30(75)$ & $30(75)$ & $\chi^{2}=0.000$ & 1.000 \\
\hline \multicolumn{5}{|l|}{ Anthropometric measures } \\
\hline Height $(\mathrm{cm})$ & $165.67 \pm 7.56$ & $165.07 \pm 5.98$ & $Z=-0.217$ & 0.828 \\
\hline Weight (kg) & $84.65 \pm 7.78$ & $81.70 \pm 5.88$ & $Z=-1.860$ & 0.063 \\
\hline BMI $\left(\mathrm{kg} / \mathrm{m}^{2}\right)$ & $31.19 \pm 2.21$ & $30.20 \pm 1.88$ & $Z=-1.742$ & 0.081 \\
\hline \multicolumn{5}{|l|}{ BMI categories $[n(\%)]$} \\
\hline Overweight & $13(32.5)$ & $14(35.0)$ & $\chi^{2}=0.056$ & 0.813 \\
\hline Obesity & $27(67.5)$ & $26(65.0)$ & & \\
\hline
\end{tabular}

BMI, body mass index; $n$, number of subjects; SD, standard deviation; $Z$, value of Mann-Whitney test, $\mathrm{X}^{2}$, value of Chi-square test. ${ }^{*} P<0.05$, statistically significant.

Table 2 Different clinical characteristics and radiological assessment of the patient group

\begin{tabular}{|c|c|}
\hline $\begin{array}{l}\text { Different clinical characteristics and } \\
\text { radiological assessment }\end{array}$ & $\begin{array}{l}\text { Patient group }(n=40) \\
\quad(\text { mean } \pm \text { SD })\end{array}$ \\
\hline Duration of the complaints (years) & $4.05 \pm 1.94$ \\
\hline \multicolumn{2}{|l|}{ Affected side (right/left) [n (\%)] } \\
\hline Unilateral & $3(7.5)$ \\
\hline Right side only & $2(5.0)$ \\
\hline Left side only & $1(2.5)$ \\
\hline Bilateral & $37(92.5)$ \\
\hline \multicolumn{2}{|l|}{ Clinical examination $[n(\%)]$} \\
\hline Presence of knee joint line tenderness & $32(80.0)$ \\
\hline Presence of knee effusion & $18(45.0)$ \\
\hline \multicolumn{2}{|l|}{ WOMAC } \\
\hline Pain subscale & $10.27 \pm 4.84$ \\
\hline Stiffness subscale & $3.95 \pm 1.67$ \\
\hline Function subscale & $24.95 \pm 8.563$ \\
\hline WOMAC total score & $39.07 \pm 14.11$ \\
\hline \multicolumn{2}{|l|}{ WOMAC total score interpretation [n (\%)] } \\
\hline Mild & $8(20.0)$ \\
\hline Moderate & $21(52.5)$ \\
\hline Severe & $9(22.5)$ \\
\hline Extreme & $2(5.0)$ \\
\hline \multicolumn{2}{|l|}{ HAQ-DI } \\
\hline HAQ-DI score & $0.07 \pm 0.11$ \\
\hline \multicolumn{2}{|l|}{ HAQ-DI score interpretation [n (\%)] } \\
\hline Mild to moderate disability & $40(100)$ \\
\hline \multicolumn{2}{|l|}{ Radiological assessment } \\
\hline \multicolumn{2}{|c|}{$\mathrm{K} / \mathrm{L}$ scale of the right knees (39 knees) $[n(\%)]$} \\
\hline Grade 1 & $6(15.4)$ \\
\hline Grade 2 & $19(48.7)$ \\
\hline Grade 3 & $12(30.8)$ \\
\hline Grade 4 & $2(5.1)$ \\
\hline \multicolumn{2}{|c|}{$\mathrm{K} / \mathrm{L}$ scale of the left knees (38 knees) $[n(\%)]$} \\
\hline Grade 1 & $5(13.2)$ \\
\hline Grade 2 & $20(52.6)$ \\
\hline Grade 3 & $11(28.9)$ \\
\hline Grade 4 & $2(5.3)$ \\
\hline
\end{tabular}

WOMAC, Western Ontario and McMaster Universities Osteoarthritis Index; HAQ-DI, Health Assessment QuestionnaireDisability Index; K/L, Kellgren-Laurence grading scale; n. number of subjects; SD, standard deviation.

its level in patients without knee joint line tenderness and the control group $(P \leq 0.0001$; Table 4$)$. This was also found for the patient group with knee effusion $(P \leq 0.0001 ;$ Table 5).

Correlations between serum IL-15 level and different demographic data, anthropometric measures, clinical characteristics, and radiological assessment of the patients are summarized in Table 6.

Figures 2-4 show graphical illustrations for the correlation between serum IL-15 level with the total WOMAC score, the HAQ-DI score, and the K/L scale of the right knee.

\section{Discussion}

Primary knee $\mathrm{OA}$ is a debilitating disease. Its cause is not yet well known. However, it appears to be a response to a complex set of various environmental, genetic, and biomechanical factors. It results in pain, with subsequent functional disabilities limiting the quality of life of the patients. OA is a major cause of disability worldwide with a great economic consequence on the society $[1-4,17]$. OA is considered to be an inflammatory condition and it is related to a group of inflammatory cytokines $[4,5,18]$. These cytokines could be good biochemical markers for primary OA. Subsequently, it is essential to detect a reliable chemical biomarker in primary knee $\mathrm{OA}$ to facilitate early assessment of OA progression and determine its severity. This also helps to determine effective therapeutic management directed toward the underlying pathophysiological mechanism of $\mathrm{OA}$ $[10,19,20]$. There are several inflammatory markers in OA $[6,7,21]$. Also, several studies have been carried out on Egyptian patients with primary knee OA that aimed to assess novel biomarkers related to the pathogenesis and/or severity of OA [22-25].

In this study, serum IL-15 level was significantly higher in the patient group in comparison with the 
Table 3 Comparison between the two studied groups regarding serum interleukin-15 level

\begin{tabular}{lccc}
\hline Serum IL-15 level $(\mathrm{pg} / \mathrm{ml})$ & Patient group $(n=40)$ & Control group $(n=40)$ & Test of significance \\
\hline Median & 60.67 & 18.99 & $Z=-7.698$ \\
Mean \pm SD & $59.29 \pm 7.41$ & $21.86 \pm 10.61$ & \\
Minimum-maximum & $42.07-68.87$ & $9.84-40.98$ & \\
\hline
\end{tabular}

IL-15, Interleukin-15; SD, standard deviation; n. number of subjects; Z, value of Mann-Whitney test for comparing between the two groups. ${ }^{*} P<0.05$, statistically significant.

\section{Figure 1}

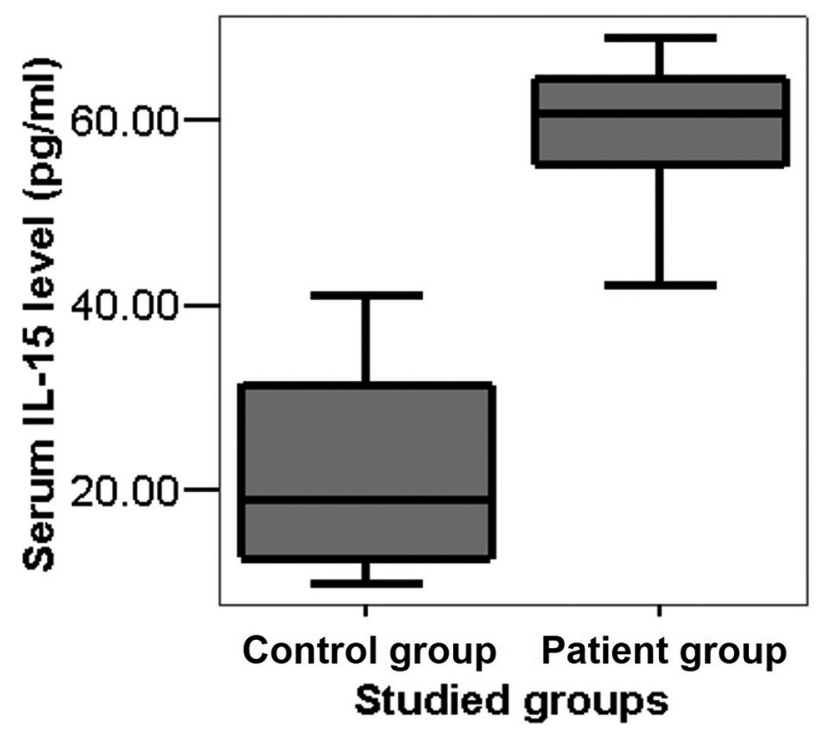

This graph illustrates the comparison between the patient group and the control group in terms of the serum interleukin- 15 level $(Z=7.698$, $P \leq 0.0001)$. The data are presented as boxplots. The boxes represent the $25^{\text {th }}$ to $75^{\text {th }}$ percentiles; the minimal and maximal values are represented as the below boxes and above boxes lines outside the boxes, respectively. IL-15, interleukin-15; Z, value of Mann-Whitney test for comparing between the two groups.

control group. This was in agreement with previous studies $[10,11,26]$. IL-15 is a proinflammatory cytokine. Subsequently, it plays a role in the pathogenesis of primary knee OA. It also plays a role in the pathogenesis of other arthritic disorders such as rheumatoid arthritis [27].

In the current study, knee joint line tenderness was present in $80 \%$ of the patients. Knee joint effusion was present in $45 \%$ of the patients studied. These were in partial agreement with Mohamed et al. [25]. They reported that knee joint line tenderness and joint effusion were present in 57.5 and $15 \%$ of their studied patients, respectively. The differences between the current study and the Mohamed et al. [25] study could be because of the inclusion of relatively more female patients than in this study and the inclusion of patients who were relatively younger than those included in this study. IL-15 serum level was significantly higher among patients with knee joint line tenderness in comparison with patients without knee joint line tenderness and the control group. Also, patients without knee joint line tenderness had a statistically significantly higher serum level of IL-15 than the control group. These were also found for knee effusion. Although IL-15 serum level was elevated in the majority of the knee OA patients (92.5\%), it was higher in patients with evidence of OA active synovitis than those OA patients with less evidence of active inflammation. These were indicators that IL-15 played a role in the inflammatory reaction in knee OA [19]. The low-grade synovitis in knee OA is associated with cartilage degeneration $[28,29]$. This inflammation is associated with inflammatory cellular infiltration of macrophages and lymphocytes with the contribution of a large group of inflammatory mediators such as tumor necrosis factor- $\alpha$ (TNF- $\alpha)$, IL-1 $\beta$, and IL-6 [30].

In the present study, there was a statistically significant negative correlation between serum IL-15 level and the duration of knee OA complaints. This was in agreement with Scanzello et al. [11]. This indicated that IL-15 is mainly elevated early in the course of OA. This could be because of the potential contribution of innate immune system activation in the early stages of knee OA pathogenesis [11].

In this study, there was a statistically significant positive correlation between serum IL-15 level and the WOMAC total score as well as WOMAC pain, stiffness, and function subscales. It was reported that inflammatory reaction increases pain sensitivity by increasing the responses of the peripheral nociceptive fibers [31]. This indicates that IL-15 plays a critical role in the pathogenesis of knee OA pain as well as stiffness. Consequently, serum IL-15 was correlated positively with the WOMAC function subscale and the WOMAC total score in addition to the statistically significant positive correlation between serum IL-15 level and the HAQ-DI score. This was in agreement with Sun et al. [10] in terms of the WOMAC pain subscale. However, no previous studies have assessed the relation between serum IL-15 level and the WOMAC total score and other WOMAC subscales as well as the HAQ-DI score. 
Table 4 Comparison between patients with knee joint line tenderness versus those without tenderness and the control group regarding serum interleukin-15 level

\begin{tabular}{|c|c|c|c|c|c|}
\hline $\begin{array}{l}\text { Serum IL-15 level } \\
(\mathrm{pg} / \mathrm{ml})\end{array}$ & $\begin{array}{l}\text { Patient group with joint line } \\
\text { tenderness }(n=32)\end{array}$ & $\begin{array}{l}\text { Patient group without joint line } \\
\text { tenderness }(n=8)\end{array}$ & $\begin{array}{l}\text { Control group } \\
\qquad(n=40)\end{array}$ & $\begin{array}{c}\text { Test of } \\
\text { significance }\end{array}$ & $P$ \\
\hline Median & 62.25 & 55.63 & 18.99 & $K=60.700$ & $\leq 0.0001^{*}$ \\
\hline Mean \pm SD & $60.64 \pm 6.74^{\dagger, \ddagger}$ & $53.91 \pm 7.96^{\dagger, \S}$ & $21.86 \pm 10.61^{\ddagger}$ & & \\
\hline Minimum-maximum & $42.53-68.87$ & $42.07-63.17$ & $9.84-40.98$ & & \\
\hline
\end{tabular}

IL-15, Interleukin-15; SD, standard deviation; $n$. number of subjects; $K$, value of Kruskal-Wallis test for comparing between the three groups. ${ }^{\star} P<0.05$, statistically significant. "Significant difference between the patient group with joint line tenderness versus the patient group without joint line tenderness $(Z=-2.384, P=0.017)$. $Z$, value of the Mann-Whitney test for comparison between the two groups. ${ }^{\ddagger}$ Significant difference between patients group with joint line tenderness versus the control group $(Z=-6.051, P \leq 0.0001)$. $Z$, value of the Mann-Whitney test for comparison between the two groups. ${ }^{\S}$ Significant difference between the patient group without joint line tenderness versus the control group $(Z=-7.253, P \leq 0.0001)$. $Z$, value of the Mann-Whitney test for comparison between the two groups.

Table 5 Comparison between patients with knee effusion versus those without effusion and the control group regarding serum interleukin-15 level

\begin{tabular}{|c|c|c|c|c|c|}
\hline $\begin{array}{l}\text { Serum IL-15 level } \\
(\mathrm{pg} / \mathrm{ml})\end{array}$ & $\begin{array}{l}\text { Patient group with knee effusion } \\
\qquad(n=18)\end{array}$ & $\begin{array}{c}\text { Patient group without knee } \\
\text { effusion }(n=22)\end{array}$ & $\begin{array}{l}\text { Control group } \\
(n=40)\end{array}$ & $\begin{array}{c}\text { Test of } \\
\text { significance }\end{array}$ & $P$ \\
\hline Median & 64.49 & 55.63 & 18.99 & $K=63.698$ & $\leq 0.0001^{*}$ \\
\hline Mean \pm SD & $64.20 \pm 3.69^{\dagger, \ddagger}$ & $55.27 \pm 7.30^{\dagger, \S}$ & $21.86 \pm 10.61^{\ddagger \S}$ & & \\
\hline Minimum-maximum & $56.31-68.87$ & $42.07-67.32$ & $9.84-40.98$ & & \\
\hline
\end{tabular}

IL-15, Interleukin-15; SD, standard deviation; $n$. number of subjects; K, value of Kruskal-Wallis test for comparing between the three groups. ${ }^{\star} P<0.05$, statistically significant. 'Significant difference between the patient group with knee effusion versus the patient group without knee effusion $(Z=-4.187, P \leq 0.0001)$. $Z$, value of the Mann-Whitney test for comparison between the two groups. "Significant difference between the patient group with knee effusion versus the control group ( $Z=-6.051, P \leq 0.0001)$. $Z$, value of the Mann-Whitney test for comparison between the two groups. ${ }^{\S}$ Significant difference between the patient group without knee effusion versus the control group $(Z=-6.473, P \leq 0.0001)$. $Z$, value of the Mann-Whitney test for comparison between the two groups.

Table 6 Correlation between serum interleukin-15 level and different demographic, anthropometric, clinical, and radiological parameters of the patient group ( $n=40$ patients)

\begin{tabular}{lcc}
\hline Different demographic, anthropometric, clinical, and radiological parameters & Serum IL-15 level (pg/ml) \\
\cline { 2 - 3 } & $r_{\mathrm{s}}$ & 0.179 \\
\hline Age (years) & 0.217 & $\leq 0.0001^{*}$ \\
Duration of complaints (years) & -0.796 & \\
Anthropometric measures & -0.076 & 0.641 \\
Height $(\mathrm{cm})$ & 0.118 & 0.467 \\
Weight $(\mathrm{kg})$ & 0.281 & 0.079 \\
BMI $\left(\mathrm{kg} / \mathrm{m}^{2}\right)$ & & $\leq .775$ \\
WOMAC & 0.726 & $\leq 0.0001^{*}$ \\
Pain subscale & 0.837 & $\leq 0.0001^{*}$ \\
Stiffness subscale & 0.877 & $\leq 0.0001^{*}$ \\
Function subscale & $\leq 0.0001^{*}$ \\
WOMAC total score & 0.776 & $\leq 0.0001^{*}$ \\
WOMAC total score interpretation & 0.720 & $\leq 0.0001^{*}$ \\
HAQ-DI score & & $\leq 0.0001^{*}$ \\
Radiological assessment & 0.815 & $\leq 0.0001^{*}$ \\
K/L scale of the right knee & 0.830 & \\
K/L scale of the left knee & & \\
\hline
\end{tabular}

BMI, body mass index; WOMAC, Western Ontario and McMaster Universities Osteoarthritis Index; HAQ-DI, Health Assessment Questionnaire-Disability Index; K/L, Kellgren-Laurence grading scale; IL-15, Interleukin-15; $r_{\mathrm{s}}$, Spearman correlation coefficient. ${ }^{*} P<0.05$, statistically significant.

There was a statistically significant positive correlation between the serum IL-15 level and the K/L scale. This indicated that IL-15 could be a marker of knee joint damage by OA. This was not in agreement with Sun et al. [10] and Scanzello et al. [11]. This could be because of differences in the age and anthropometric measures of the patients included in their studies and the current study. Also, Scanzello et al. [11] assessed the synovial fluid level of IL-15 and not the serum level.

The statistically significant positive correlations between serum IL-15 level with different aspects of primary knee $\mathrm{OA}$ indicated that the higher the serum level of IL-15, the more the patient perceived pain, the worse the stiffness and functional disabilities, and the 
Figure 2

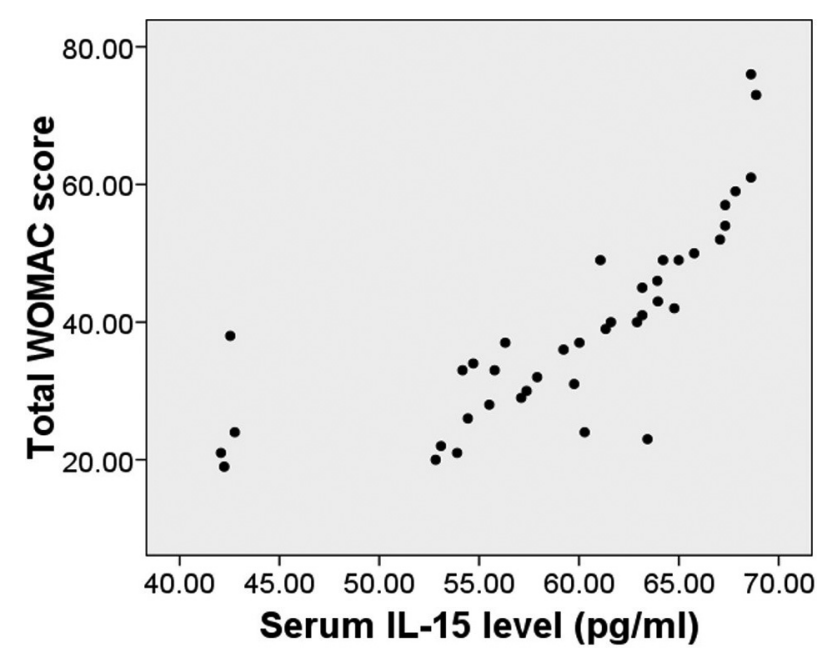

This graph shows the correlation between serum interleukin- 15 level and the total Western Ontario and McMaster Universities Osteoarthritis Index score $\left(r_{\mathrm{s}}=0.877, P \leq 0.0001\right)$. IL-15, interleukin-15; $r_{\mathrm{s}}$, Spearman correlation coefficient; WOMAC, Western Ontario and McMaster Universities Osteoarthritis Index.

\section{Figure 4}

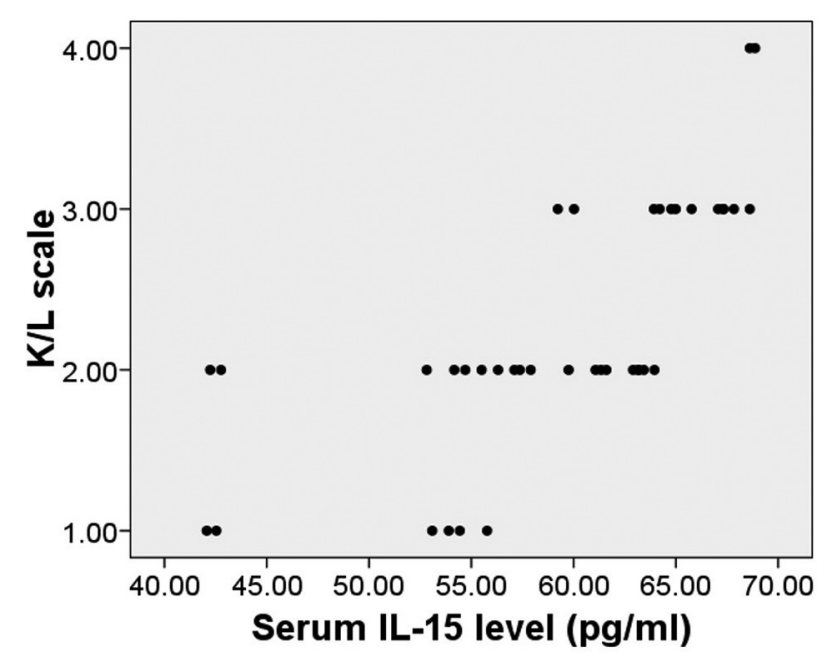

This graph shows the correlation between serum interleukin-15 level and the Kellgren-Laurence grading scale of the right knee $\left(r_{\mathrm{s}}=0.815\right.$, $P \leq 0.0001)$. IL-15, interleukin-15; K/L, Kellgren-Laurence grading scale; $r_{\mathrm{s}}$, Spearman correlation coefficient.

more the joint radiological damage. Therefore, IL-15 could be a potential serum biomarker for the detection of the severity of primary knee OA [6]. Also, IL-15 could be a potential target for a therapeutic intervention in primary knee OA [6].

IL-15 affects all aspects of primary knee OA in terms of pain, stiffness, functional disability, and radiological deterioration. IL-15 could be considered an OA biomarker that provides important information on disease severity and radiological damage with
Figure 3

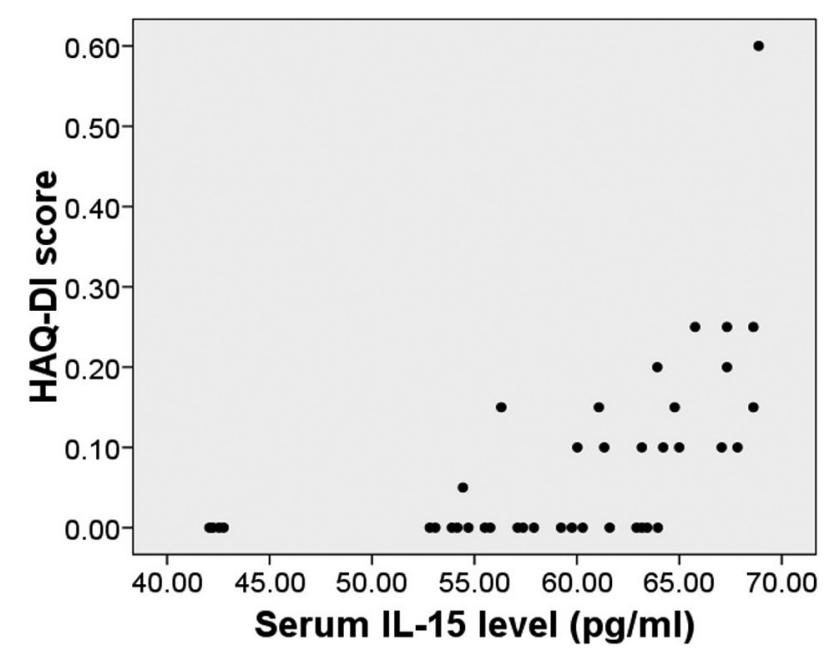

This graph shows the correlation between serum interleukin-15 level and the Health Assessment Questionnaire-Disability Index score $\left(r_{\mathrm{s}}=0.720, P \leq 0.0001\right)$. HAQ-DI, Health Assessment QuestionnaireDisability Index; IL-15, interleukin-15; $r_{\mathrm{s}}$, Spearman correlation coefficient.

prediction of disease progression. This was in agreement with the concept that systemic inflammatory markers are associated with a severe course of OA [6].

The results of this study showed that IL-15 played a role in the inflammatory reaction in knee OA. IL-15 is a cytokine produced in the innate immune response as IL-1 $\beta, \quad$ TNF- $\alpha$, and IL-6 [11]. IL-15 is a proinflammatory cytokine. It has many physiological functions. It is produced by many cell types. It is produced by activated lymphocytes and dendritic cells, in addition to synovial fibroblasts and macrophages [32]. It acts by modulating immune cells of the innate and adaptive immune systems [33]. IL-15 has the ability to recruit and activate the natural killer cells and CD8 T lymphocytes within the OA joint [9,34-36]. It was described as a $T$-cell growth factor [9]. It promotes the production of other proinflammatory cytokines such as TNF- $\alpha$ and IL-6 by the synovial T-cells within the synovial membrane [30]. These cytokines have been found to contribute in the pathogenesis of OA by increasing articular cartilage degeneration [37]. IL-15 has the ability to induce matrix metalloproteinase production and mainly matrix metalloproteinase-1 production by fibroblasts. All these promote articular cartilage and subchondral bone damage [38].

Therefore, the proinflammatory effects of IL-15 explain the statistically significant correlations found in this study [27]. Subsequently, studies on targeting 
IL-15 in treatment of primary knee OA could be expected to result in adequate therapeutic improvement in OA.

This study had some limitations. First, this crosssectional study included a relatively small number of patients. Further studies with more patients are needed to verify the results of the current study. Second, the current study only assessed the serum IL-15 level. It did not assess the level of IL-15 in the synovial fluid aspirated from knee OA joints, which could provide new information on its role in the pathogenesis of knee OA. Third, this study only assessed the serum IL-15 level and did not investigate other inflammatory mediators such as IL-1 $\beta$ to assess the relationship between serum IL-15 and other cytokines in patients with primary knee OA.

\section{Conclusion}

Serum IL-15 is elevated and correlated positively with pain, stiffness, functional disabilities, as well as radiological damage in primary knee OA. This suggests that IL-15 plays an important critical role in the pathogenesis of primary knee OA-related pain, stiffness, and joint damage. IL-15 might be a potential biomarker for assessing the severity of primary knee OA. Further studies on the efficacy of blocking IL-15 signaling pathways to control and delay primary knee OA degenerative processes are recommended.

\section{Acknowledgements}

The authors are grateful to Maria Kamal Aziz Saba for her assistance in the preparation of the figures.

\section{Financial support and sponsorship}

Nil.

\section{Conflicts of interest}

There are no conflicts of interest.

\section{References}

1 Abhishek A, Doherty M. Diagnosis and clinical presentation of osteoarthritis. Rheum Dis Clin North Am 2013; 39:45-66.

2 Lawrence R, Felson D, Helmick C. Estimates of the prevalence of arthritis and other rheumatic conditions in the United States. Part II. Arthritis Rheum 2008; 58:26-35.

3 Hunter DJ, Johnson VL. The epidemiology of osteoarthritis. Best Pract Res Clin Rheumatol 2014; 28:5-15.

4 Palazzo C, Nguyen C, Lefevre-Colau M, Rannou F, Poiraudeau S. Risk factors and burden of osteoarthritis. Ann Phys Rehabil Med 2016; 59:134-138.

5 Felson D. An update on the pathogenesis and epidemiology of osteoarthritis. Radiol Clin North Am 2004; 42:1-9.

6 Kapoor M, Martel-Pelletier J, Lajeunesse D, Pelletier J, Fahmi H. Role of proinflammatory cytokines in the pathophysiology of osteoarthritis. Nat Rev Rheumatol 2011; 7:33-42.
7 Wojdasiewicz P, Poniatowski LA, Szukiewicz D. The role of inflammatory and anti-inflammatory cytokines in the pathogenesis of osteoarthritis. Mediators Inflamm 2014; 2014:561459.

8 Han MY, Dai JJ, Zhang Y, Lin Q, Jiang M, Xu XY, et al. Identification of osteoarthritis biomarkers by proteomic analysis of synovial fluid. J Int Med Res 2012; 40:2243-2250.

9 Dubois S, Mariner J, Waldmann TA, Tagaya Y. IL-15R $\alpha$ recycles and presents IL-15 in trans to neighboring cells. Immunity 2002; 17:537-547.

10 Sun JM, Sun LZ, Liu J, Su BH, Shi L. Serum interleukin-15 levels are associated with severity of pain in patients with knee osteoarthritis. Dis Markers 2013; 35:203-206.

11 Scanzello CR, Umoh E, Pessler F, Diaz-Torne C, Miles T, DiCarlo E, et al. Local cytokine profiles in knee osteoarthritis: elevated synovial fluid interleukin-15 differentiates early from end-stage disease. Osteoarthritis Cartilage 2009; 17:1040-1048.

12 Altman R, Asch E, Bloch D. Development of criteria for the classification and reporting of osteoarthritis. Classification of osteoarthritis of the knee. Diagnostic and therapeutic criteria committee of the American Rheumatism Association. Arthritis Rheum 1986; 29:1039-1049.

13 McConnell S, Kolopack P, Davis AM. The Western Ontario and McMaster Universities Arthritis Index (WOMAC): a review of its utility and measurement properties. Arthritis Rheum 2001; 45:453-461.

14 Bruce B, Fries J. The Health Assessment Questionnaire (HAQ). Clin Exp Rheumatol 2005; 23:14-18.

15 Emrani P, Katz J, Kessler C, Reichmann W, Wright E, McAlindon T, et al. Joint space narrowing and Kellgren-Lawrence progression in knee osteoarthritis: an analytic literature synthesis. Osteoarthritis Cartilage 2008; 16:873-882.

16 SPSS. Statistical package for the social sciences, version 17. London University of Cambridge Computing Service; 2007.

17 Appuhamy S, Munidasa SMPD. Study of epidemiology, symptom variability and knowledge assessment of knee joint osteoarthritis patients in Sri Lanka [abstract]. Int J Rheum Dis 2019; 22:48.

18 Mora JC, Przkora R, Cruz-Almeida Y. Knee osteoarthritis: pathophysiology and current treatment modalities. J Pain Res 2018; 11:2189-2196.

19 Berenbaum F. Osteoarthritis as an inflammatory disease (osteoarthritis is not osteoarthrosis!). Osteoarthritis Cartilage 2013; 21:16-21.

20 Mabey T, Honsawek S. Cytokines as biochemical markers for knee osteoarthritis. World J Orthop 2015; 6:95-105.

21 Nguyen LT, Sharma AR, Chakraborty C, Saibaba B, Ahn ME, Lee SS Review of prospects of biological fluid biomarkers in osteoarthritis. Int J Mol Sci 2017; 18:601

22 Abdel Ghany HM, El Tawab SS, Moghazy AM. Urinary C-termina telopeptide of type II collagen, radiological severity, and functiona assessment in knee osteoarthritis: are these related? Egypt Rheumatol Rehabil 2016; 43:73-77.

23 Gaballah A, Hussein N, Risk M, Elsawy N, Elabasiry S. Correlation between synovial vascular endothelial growth factor, clinical, functional and radiological manifestations in knee osteoarthritis. Egypt Rheumatol 2016; 38:29-34.

24 Ibrahim IK, Shahine EM, El-Hadedy AS, Saba EKA, Hussein GSA. Role of interleukin-18 in primary knee osteoarthritis: clinical, laboratory and radiological study [abstract]. Int J Med Health Sci 2016; 3:123.

25 Mohamed SA, Neseem NO, Metwally SS, Farag SEDM. IL-17 in primary knee osteoarthritis and its relation with severity of the disease. Int $\mathrm{J}$ Clin Rheumatol 2018; 13:364-369.

26 Ling SM, Patel DD, Garnero P, Zhan M, Vaduganathan M, Muller D, et al. Serum protein signatures detect early radiographic osteoarthritis. Osteoarthritis Cartilage 2009; 17:43-48.

27 Carroll HP, Paunovic V, Gadina M. Signaling, inflammation and arthritis: crossed signals: the role of interleukin-15 and -18 in autoimmunity. Rheumatology 2008; 47:1269-1277.

28 Hill CL, Hunter DJ, Niu J, Clancy M, Guermazi A, Genant H, et al. Synovitis detected on magnetic resonance imaging and its relation to pain and cartilage loss in knee osteoarthritis. Ann Rheum Dis 2007; 66:1599-1603.

29 Ayral X, Pickering EH, Woodworth TG, Mackillop N, Dougados M. Synovitis: a potential predictive factor of structural progression of medial tibiofemoral knee osteoarthritis - results of a 1-year longitudinal arthroscopic study in 422 patients. Osteoarthritis Cartilage 2005; 13:361-367.

30 Mcinnes IB, Al-Mughales J, Field M, Leung BP, Huang FP, Dixon R, et al The role of interleukin-15 in T-cell migration and activation in rheumatoid arthritis. Nat Med 1996; 2:175-182. 
31 Mathiessen A, Conaghan PG. Synovitis in osteoarthritis: current understanding with therapeutic implications. Arthritis Res Ther 2017; 19:18.

32 Waldmann TA, Dubois S, Tagaya Y. Contrasting roles of IL-2 and IL-15 in the life and death of lymphocytes: implications for immunotherapy. Immunity $2001 ; 14: 105-110$.

33 Perera PY, Lichy JH, Waldmann TA, Perera LP. The role of interleukin-15 in inflammation and immune responses to infection: implications for its therapeutic use. Microbes Infect 2012; 14:247-261.

34 Kobayashi H, Dubois S, Sato N, Sabzevari H, Sakai Y, Waldmann TA, et al. Role of trans-cellular IL-15 presentation in the activation of NK cellmediated killing, which leads to enhanced tumor immunosurveillance. Blood 2005; 105:721-727.

35 Klebanoff CA, Finkelstein SE, Surman DR, Lichtman MK, Gattinoni L, Theoret MR, et al. IL-15 enhances the in vivo antitumor activity of tumor-reactive CD8+T cells. Proc Natl Acad Sci USA 2004; 101:1969-1974.

36 Judge AD, Zhang X, Fujii H, Surh CD, Sprent J. Interleukin- 15 controls both proliferation and survival of a subset of memory-phenotype CD8(+) T cells. J Exp Med 2002; 196:935-946.

37 Orita S, Koshi T, Mitsuka T, Miyagi M, Inoue G, Arai G, et al. Associations between proinflammatory cytokines in the synovial fluid and radiographic grading and pain-related scores in 47 consecutive patients with osteoarthritis of the knee. BMC Musculoskelet Disord $2011 ; 12: 144$.

38 Constantinescu CS, Grygar C, Kappos L, Leppert D. Interleukin-15 stimulates production of matrix metalloproteinase- 9 and tissue inhibitor of metalloproteinase-1 by human peripheral blood mononuclear cells. Cytokine 2001; 13:244-247. 